Mitchell, P. \& Moyle, J. (1957). J. gen. Microbiol. 16, 184-194

\title{
Autolytic Release and Osmotic Properties of 'Protoplasts' from Staphylococcus aureus
}

\author{
By P. MITCHELL AND JENNIFER MOYLE \\ Zoology Department, University of Edinburgh
}

SUMMARY: The cell wall of exponential phase Staphylococcus aureus (strain Duncan) loses its tensile strength in $c .2 \mathrm{hr}$. when the organisms are incubated at $25^{\circ}$ in 1.2 M-sucrose at $\mathrm{pH} \mathrm{5.8}$ and ionic strength $0 \cdot 3$. The 'protoplasts' thus released from the mechanical protection of the cell wall are stable in $1.2 \mathrm{~m}$-sucrose but lyse in media of lower osmotic pressure. The mean internal osmotic pressure of the 'protoplasts' is $c .20$ atmospheres; they are permeable to glycerol but not to sucrose or $\mathrm{NaCl}$. The rate of 'protoplast' release varies with the rate of growth of the organisms at harvesting. After osmotic explosion of 'protoplasts' released from slowly growing organisms the plasma membranes may be recovered as spherical shells which disintegrate and condense into small particles on washing, and $75 \%$ of the weight of the cell walls may be recovered as hemispherical shells.

The aim of the work described in this paper was to develop a method for releasing the protoplasts of Staphylococcus aureus (strain Duncan) from the protection of the cell wall so as to facilitate the study of the structure and function of the plasma membrane (Mitchell \& Moyle, 1956 $a$ ). Since staphylococci had been reported to be somewhat sensitive to lysozyme under certain conditions (Webb, 1948; Kern, Kingkade, Kern \& Behrens, 1951) we decided to investigate the possibility of releasing stable 'protoplasts' of staphylococci by modifications of the technique of Weibull (1953) similar to those which we developed for the release of the protoplasts of Micrococcus lysodeikticus and Sarcina lutea (Mitchell \& Moyle, 1956b).

\section{METHODS}

Growth and preparation of organisms. Cultures were grown at $25^{\circ}$ in a medium containing $3 \%(\mathrm{w} / \mathrm{v})$ tryptic digest of casein, $1 \%$ glucose and $0 \cdot 1 \%$ Marmite, either in Roux bottles or using the rotated flask technique (Mitchell, 1949). The organisms were harvested by centrifugation, washed once with distilled water and suspended at a concentration corresponding to c. $100 \mathrm{mg}$. dry weight $/ \mathrm{ml}$. in distilled water.

Measurement of turbidity and dry weight. The extinction of $1 \mathrm{~cm}$. depth of bacterial suspension was measured at a wavelength of $700 \mathrm{~m} \mu$., using the Beckman model DU spectrophotometer. The suspensions were diluted to give readings of $\log _{10}\left(I_{0} / I\right)$ between 0.1 and 0.2 so that, the extinction being proportional to dry weight in this range, the dry weight could be estimated by multiplying the extinction by a factor. The factors for the different organisms were determined by calibrating the extinction against the dry-weight concentration estimated by drying $c .100 \mathrm{mg}$. samples to constant weight at $105^{\circ}$. 
Light microscopy. The intact organisms, 'protoplasts' and membranes were examined with a Zeiss binocular phase-contrast microscope in films of aqueous solution sealed between slide and coverslip with vaseline.

Electron microscopy. The cell walls and plasma membranes were washed with large volumes of dust-free distilled water. Drops of dilute suspension in distilled water were placed on collodion film-covered specimen grids. The greater part of the drops was removed by touching them momentarily with a piece of clean filter-paper, and the remainder of the material was rapidly dried on the grids in vacuo over $\mathrm{P}_{2} \mathrm{O}_{5}$. The specimens thus prepared were shadowed at an angle of $15^{\circ}$ to the surface of the collodion film with goldpalladium and examined and photographed with the Siemens Elmiskop 1 electron microscope operated by Dr K. Deutsch.

Index of osmotic fragility. Samples $(0 \cdot 1 \mathrm{ml}$.) of the suspensions of organisms undergoing 'protoplast' release were pipetted into paired $5 \mathrm{ml}$. samples of $1.2 \mathrm{M}-\mathrm{NaCl}$ in $0.01 \mathrm{M}$-sodium phosphate and $0.01 \mathrm{M}$-sodium phosphate buffer alone at $\mathrm{pH} 6.8$. The turbidities of the suspensions in the paired tubes were measured after $20 \mathrm{~min}$. at $20^{\circ}$. It was often convenient to express these turbidities as percentages of the values obtained at the beginning of incubation in the 'protoplast'-releasing solutions when all the organisms were still osmotically insensitive, and to write an index of osmotic fragility $a / b, a$ being the percentage of the initial turbidity in the buffer alone and $b$ being that in the buffered saline. If the 'protoplasts' of the staphylococci studied here behaved like the protoplasts of Micrococcus lysodeikticus and Sarcina lutea (Mitchell \& Moyle, 1956b), they would lyse in buffer alone but not in buffered $1.2 \mathrm{M}-\mathrm{NaCl}$, and the turbidity of the lysed 'protoplasts' would be very small compared with that of the intact 'protoplasts'. The ratio $a / b$ would therefore fall from unity towards zero as the organisms became osmotically fragile and the proportion of osmotically fragile organisms would be approximately $1-(a / b)$.

\section{RESULTS}

Seven strains of Staphylococcus aureus (strains Duncan, Pusey, 9104 and 9963) and $S$. albus (strains 7834, 9958 and 9966) were grown in Roux bottles and harvested during the phase of decelerated growth. The organisms were suspended at a final concentration corresponding to $c .5 \mathrm{mg}$. dry weight $/ \mathrm{ml}$. with $0.5 \mathrm{mg}$. crystalline egg white lysozyme $/ \mathrm{ml}$. in $1.2 \mathrm{M}$-sucrose solutions in either $0.02 \mathrm{M}$-sodium phosphate buffer at $\mathrm{pH} 6.8$ or in $0.02 \mathrm{M}$-tris-(hydroxymethyl)-aminomethane acetate buffer at $\mathrm{pH} 8 \cdot 4$ at $25^{\circ}$. Similar suspensions in which only the lysozyme was omitted were used as controls. The apparent rate of 'protoplast' release is shown by the index $a / b$ (as defined above) in Table 1 . Incubation in the presence of lysozyme at pH 6.8 made all the organisms appreciably more fragile to suspension in $0.01 \mathrm{M}$-phosphate buffer than to suspension in buffered $1.2 \mathrm{M}-\mathrm{NaCl}$ ( $a$ less than $b$ ), and the same was true for most of the organisms incubated at $\mathrm{pH} \mathrm{8.4}$, although at this $\mathrm{pH}$ value the fragility of the organisms either before or after pipetting into the buffered $\mathrm{NaCl}$ was generally greater than at $\mathrm{pH} 6 \cdot 8$. 
In one case (7834) the fragility in buffered $\mathrm{NaCl}$ was greater than in buffer alone. Even in the absence of lysozyme, however, there was a significant increase in the osmotic fragility of all the organisms incubated at $\mathrm{pH} 6.8$ and in some of them incubated at $\mathrm{pH} \mathbf{8 \cdot 4}$. This experiment suggested that by appropriately adjusting the conditions it might be possible to release the protoplasts of staphylococci from the cell wall without the addition of lysozyme. Clearly, it would be advantageous if it were possible to eliminate the necessity

\section{Table 1. Development of osmotic fragility in seven strains of staphylococcus}

The organisms were incubated at a concentration of $5 \mathrm{mg} . / \mathrm{ml}$. at $25^{\circ}$ in $1.2 \mathrm{M}$-sucrose buffered with $0 \cdot 02 \mathrm{M}$-acetate $(\mathrm{pH} 6 \cdot 8$ ) or $0 \cdot 02 \mathrm{M}$-tris (pH 8.4) without $(-)$ or with $(+) 0.5 \mathrm{mg}$. egg-white lysozyme/ml. Ratios $a / b$ in the body of the table represent percentage initial turbidity on pipetting $0.1 \mathrm{ml}$. samples of cell suspension into $5 \mathrm{ml}$. 0.01 $\mathrm{M}$-sodium phosphate buffer at $\mathrm{pH} 6.8(a)$ without and $(b)$ containing $1.2 \mathrm{M}-\mathrm{NaCl}$. The values of $a / b$ at zero time are, of course, $100 / 100$.

Strain of staphylococcus

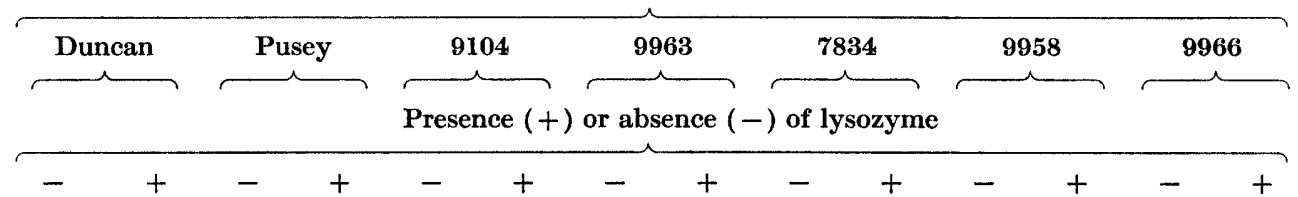

Time (hr.) $\mathrm{pH}$

\begin{tabular}{|c|c|c|c|c|c|c|c|c|c|c|c|c|c|c|}
\hline 20 & (98/99 & $41 / 74$ & $94 / 97$ & $66 / 71$ & $83 / 93$ & $27 / 66$ & $96 / 99$ & $66 / 78$ & $89 / 91$ & $29 / 68$ & $60 / 73$ & $16 / 36$ & $55 / 75$ & $22 / 39$ \\
\hline 27 & $94 / 96$ & $24 / 65$ & $90 / 93$ & $47 / 60$ & $76 / 87$ & $15 / 58$ & $93 / 99$ & $36 / 62$ & $86 / 85$ & $25 / 68$ & • & - & , & \\
\hline 46 & $90 / 95$ & $15 / 54$ & $81 / 89$ & $25 / 44$ & $63 / 80$ & $8 / 46$ & $84 / 94$ & $18 / 51$ & $73 / 83$ & $21 / 45$ & - & - & • & \\
\hline 73 & $78 / 94$ & - & $79 / 90$ & . & $58 / 80$ & - & $83 / 94$ & . & $71 / 81$ & . & - & - & • & \\
\hline 20 & $(99 / 104$ & $34 / 72$ & $94 / 99$ & $57 / 64$ & $76 / 83$ & $24 / 59$ & $90 / 94$ & $49 / 67$ & $91 / 93$ & $37 / 411$ & $69 / 78$ & $30 / 37$ & $41 / 58$ & $38 / 37$ \\
\hline 27 & $81 / 92$ & $19 / 60$ & $90 / 90$ & $32 / 50$ & $69 / 75$ & $11 / 48$ & $84 / 91$ & $26 / 52$ & $89 / 89$ & $30 / 29$ & • & • & - & . \\
\hline 48 & $73 / 84$ & $6 / 49$ & $84 / 87$ & $15 / 34$ & $52 / 67$ & $8 / 44$ & $75 / 84$ & $11 / 36$ & $87 / 82$ & $30 / 20$ & $\cdot$ & . & * & . \\
\hline 73 & $52 / 79$ & . & $76 / 82$ & • & $36 / 61$ & - & $63 / 81$ & - & $73 / 74$ & - & - & . & . & . \\
\hline
\end{tabular}

for contaminating the protoplasts with added lysozyme. Since Staphylococcus aureus (strain Duncan) -which had already been the object of osmotic studies-appeared to behave typically among the seven organisms tested, we investigated the factors which determine the rate of development of osmotic fragility in this organism.

\section{Effect of $\mathrm{pH}$ value}

Fig. 1 shows the dependence of the rate of development of osmotic fragility on the $\mathrm{pH}$ value, measured by the rate of change of $a / b$ in suspensions of Staphylococcus aureus (strain Duncan), harvested at a density corresponding to $c .2 \mathrm{mg}$. dry weight $/ \mathrm{ml}$. from rotated flask cultures, and incubated at $25^{\circ}$ in $1.2 \mathrm{M}$-sucrose containing $0.2 \mathrm{M}-\mathrm{NaCl}$, buffered with $0.01 \mathrm{M}$-(sodium acetate/acetic acid) (-०-) or with $0 \cdot 01 \mathrm{M}$-sodium phosphates $(--)$ and containing 0.01 M-sodium iodoacetate to prevent acid production and drift of $\mathrm{pH}$. The presence of iodoacetate was shown to be without effect on the rate of development of osmotic fragility (see below). The optimum rate is near $\mathrm{pH} 6$. 


\section{Effect of salt concentration}

Fig. 2 shows the dependence of the rate of development of osmotic fragility of Staphylococcus aureus (strain Duncan) on salt concentration. The measurements were made as above on suspensions incubated at $25^{\circ}$ in $1.2 \mathrm{M}$-sucrose buffered at $\mathrm{pH} 5.8$ with a range of concentrations of acetate buffer containing 9 mole NaAc to 1 mole HAc. The rate is nearly linear with salt concentration up to ionic strength $\mathbf{0} \cdot \mathbf{3}$, at which there is a sharp optimum. Identical results were obtained when the ionic strength was varied by adding $\mathrm{NaCl}$ to a constant concentration $(0 \cdot 02 \mathrm{M})$ of acetate buffer.

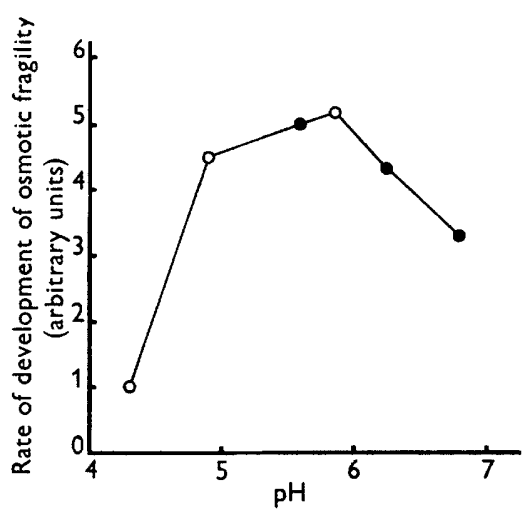

Fig. 1

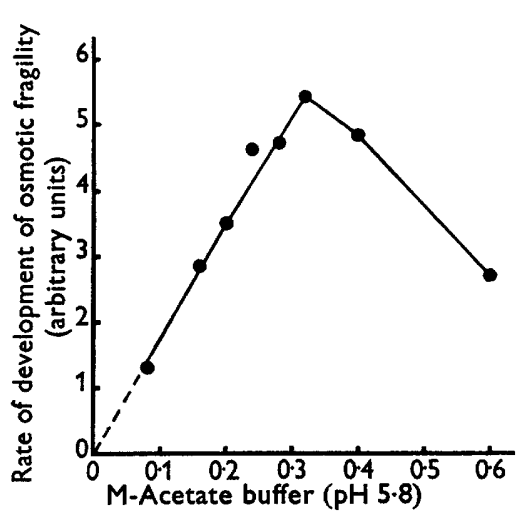

Fig. 2

Fig. 1. Effect of $\mathrm{pH}$ on the rate of development of osmotic fragility of Staphylococcus aureus (strain Duncan) at $25^{\circ}$ in $1.2 \mathrm{M}$-sucrose containing $0.2 \mathrm{M}-\mathrm{NaCl}$ and $0.01 \mathrm{M}$-sodium iodoacetate buffered with either $0.01 \mathrm{M}$-(sodium acetate/acetic acid) (-०-) or with 0.01 M-sodium phosphates ( $\rightarrow-)$.

Fig. 2. Effect of salt concentration on the rate of development of osmotic fragility of Staphylococcus aureus (strain Duncan) at $25^{\circ}$ in $1.2 \mathrm{M}$-sucrose buffered at pH 5.8 with a range of concentrations of acetate buffer containing 9 mole NaAc to 1 mole HAc.

\section{Effect of some potential inhibitors and activators}

The presence of $0.01 \mathrm{M}$-sodium ethylenediamine tetra-acetate was found to inhibit by $75 \%$ the rate of development of osmotic fragility of Staphylococcus aureus (strain Duncan) in $1.2 \mathrm{M}$-sucrose containing $0 \cdot 33 \mathrm{M}$-acetate buffer at $\mathrm{pH} 5 \cdot 8$. The addition of $\mathrm{MgCl}_{2}$ or $\mathrm{LaCl}_{3}$ to the autolysis medium at ionic strength 0.3 at $\mathrm{pH} 5.8$ did not cause activation of the development of osmotic fragility nor was the rate affected by the presence of $0.01 \mathrm{M}-\mathrm{KCN}, 0.01 \mathrm{M}$-sodium iodoacetate, 0.01 M-sodium thioglycollate or by aeration.

\section{Effect of age of culture}

Fig. 3 shows the time course of the logarithm of the dry-weight concentration of Staphylococcus aureus (strain Duncan) growing at $\mathbf{2 5}^{\circ}$ in a rotated flask, and the rate of development of osmotic fragility of the organisms of corresponding age incubated at $25^{\circ}$ in $1.2 \mathrm{M}$-sucrose containing acetate buffer at pH 6.8 of ionic strength $0 \cdot 3$. The rate of development of osmotic fragility was 
in this case measured by the apparent time taken for half the organisms to become osmotically fragile (when $a / b=0.5$ ): this being determined from plots of the time course of $\left.a(-)_{-}\right)$and $b(-0)$ such, for example, as that shown in Fig. 4 for the organisms harvested at a concentration corresponding to $0.95 \mathrm{mg}$. dry weight $/ \mathrm{ml}$. For mean generation times shorter than $2 \mathrm{hr}$. the rate of development of osmotic fragility rises approximately linearly with the rate of growth, but for mean generation times longer than $2 \mathrm{hr}$. the rate of appearance of osmotic fragility approaches zero. Rapid growth is therefore

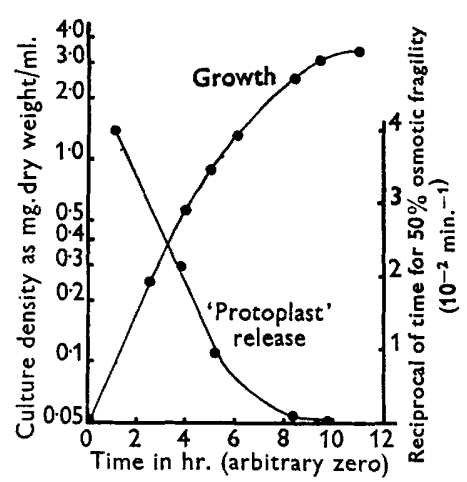

Fig. 3

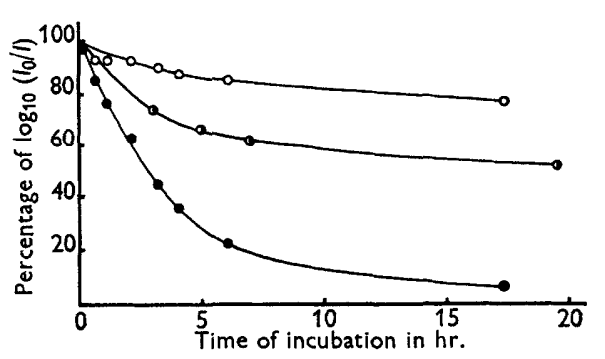

Fig. 4

Fig. 3. Time course of growth of cultures of Staphylococcus aureus (strain Duncan) at $25^{\circ}$ as $\mathrm{mg}$. dry weight of organisms $/ \mathrm{ml}$. on logarithmic scale, with plot of rate of development of osmotic fragility in organisms of corresponding age on incubation at $25^{\circ}$ in $1 \cdot 2 \mathrm{M}$-sucrose containing acetate buffer of ionic strength $0 \cdot 3$ at pH $5 \cdot 8$.

Fig. 4. Time course of development of osmotic fragility of Staphylococcus aureus (strain Duncan) harvested at a concentration corresponding to $0.95 \mathrm{mg}$. dry weight $/ \mathrm{ml}$, and of autolysis of cell walls of organisms of the same age. Organisms incubated at $25^{\circ}$ in 1.2 M-sucrose containing acetate buffer of ionic strength 0.3 at $\mathrm{pH} 6 \cdot 8$. The osmotic fragility is given by percentage initial turbidity of $0.1 \mathrm{ml}$. samples of incubated suspension pipetted into $5 \mathrm{ml}$. samples of $(a) 0.01 \mathrm{M}$-phosphate buffer alone at pH $6.8(-\bullet-)$ and (b) the same buffer containing $1 \cdot 2 \mathrm{M}-\mathrm{NaCl}(-\infty)$. The isolated cell walls were incubated in the same medium as whole organisms and degree of autolysis given by turbidity of samples corresponding to $(a)$ above $(-0-)$.

a prerequisite for the rapid development of osmotic fragility, the time taken for $50 \%$ of the organisms from the exponential phase of growth to become osmotically fragile being only $25 \mathrm{~min}$. under the conditions of our experiments.

\section{Internal osmotic pressure}

The 'protoplasts', obtained from organisms harvested at a concentration corresponding to $c .1 \cdot 1 \mathrm{mg}$. dry weight/ml., by incubation in $1.2 \mathrm{M}$-sucrose containing $0.33 \mathrm{M}$-acetate buffer at pH 5.8 at $25^{\circ}$ for $20 \mathrm{hr}$. were generally found to lyse at a rate not greater than $5 \% / \mathrm{hr}$. when $0.1 \mathrm{ml}$. samples were pipetted into $5 \mathrm{ml}$. samples of $1.2 \mathrm{M}-\mathrm{NaCl}$ at $20^{\circ}$. These 'protoplasts' were considered to be suitable for osmotic studies. Fig. 5 ( $(-)$ ) shows the turbidity 
of the 'protoplasts' suspended in a range of concentrations of $\mathrm{NaCl}$ buffered with $0.01 \mathrm{M}$-sodium phosphate at $\mathrm{pH} 6 \cdot 8$. As in the case of the protoplasts of Micrococcus lysodeikticus and Sarcina lutea (Mitchell \& Moyle, 1956b) the 'protoplasts' of Staphylococcus aureus require an external concentration of c. $0.7 \mathrm{M}-\mathrm{NaCl}$ to stabilize half of them and, since they are not stabilized by 1.2 M-glycerol (Fig. 5, - - ) , it is evident that the mean internal osmotic pressure must be $c .20$ atmospheres, the internal medium of the organisms being separated from the suspension medium by a semipermeable plasma membrane, permeable to glycerol but not to sucrose and $\mathrm{NaCl}$.

\section{Respiration of 'protoplasts'}

The $Q_{\mathrm{o}_{2}}$ for the intact organisms and 'protoplasts' were measured at $25^{\circ}$ in $1.2 \mathrm{M}$-sucrose containing $0.33 \mathrm{M}$-acetate buffer at $\mathrm{pH} 5.8$ in Warburg manometers as recommended by Dixon (1934). A typical batch of the normal organisms harvested at a density corresponding to $1.42 \mathrm{mg}$. dry weight/ml. gave $Q_{\mathrm{o}_{2}}$ values of $\mathbf{9 \cdot 6}$ for residual respiration and $\mathbf{7 \cdot 5}$ for glucose oxidation,

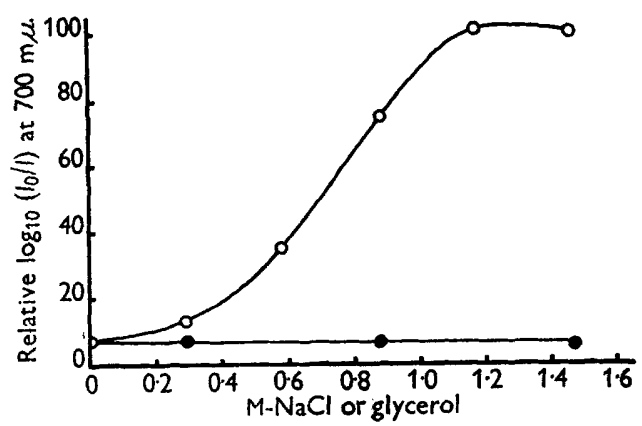

Fig. 5

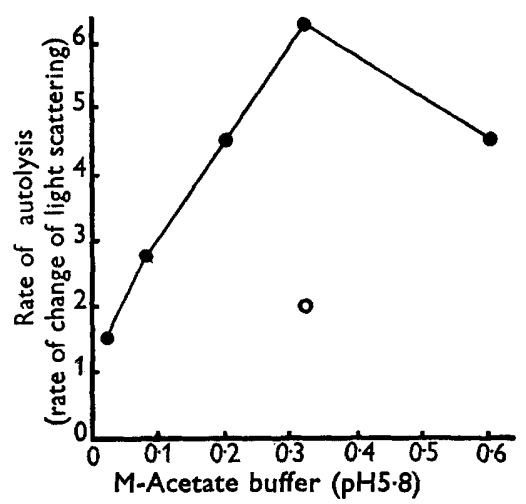

Fig. 6

Fig. 5. Dependence of stability of 'protoplasts' of Staphylococcus aureus (strain Duncan) on the concentration of $\mathrm{NaCl}(-\circ)$ and of glycerol (-๑), buffered at $\mathrm{pH} 6.8$ with sodium phosphates, indicated by the turbidity of the suspensions expressed as a percentage of the value in $1.2 \mathrm{M}-\mathrm{NaCl}$.

Fig. 6. Dependence of rate of autolysis of cell walls of Staphylococcus aureus (strain Duncan) on salt concentration measured by the rate of change of turbidity, under conditions corresponding to those of Fig. 2 for the intact organisms (- - ). The isolated point (0) shows the effect of the presence of $0.01 \mathrm{~m}$-sodium ethylenediamine tetra-acetate.

determined immediately after harvesting and washing. The 'protoplasts' prepared from these organisms by treatment as in the above paragraph for $40 \mathrm{hr}$. gave $Q_{\mathrm{O}_{2}}$ values of $9 \cdot 6$ for residual respiration and $6 \cdot 3$ for glucose oxidation. Thus, the residual respiration of intact organisms and 'protoplasts' is the same but glucose oxidation is depressed to $84 \%$ of its normal value in the 'protoplasts'. We may therefore infer that in spite of the prolonged autolytic treatment the enzyme systems of the 'protoplasts' remain virtually intact. 


\section{Autolytic systems of the cell walls}

Since the development of fragility of the organisms must depend on loss of tensile strength of the cell wall, it was reasonable to suppose that osmotic fragility might be due to digestion of cell wall by an autolytic system within the organism. Attempts to obtain an autolytic system from the soluble fraction of Staphylococcus aureus (strain Duncan) after mechanical disintegration and fractionation as previously described (Mitchell \& Moyle, 1951) were unsuccessful. However, the cell-wall fraction was found to autolyse under the same conditions and at about the same rate as whole organisms. The rate of autolysis of cell walls obtained from a culture harvested at a density corresponding to $0.95 \mathrm{mg}$. dry weight $/ \mathrm{ml}$. is shown in Fig. 4 (-) - by the turbidity plotted as a fraction of the initial value, the conditions of incubation being identical to those used for the intact organism described in the same figure. Fig. 6 shows the dependence of the rate of autolysis of the cell walls (measured by rate of change of turbidity) on salt concentration under conditions corresponding to those of Fig. 2. At ionic strength $0.3,0.01 \mathrm{M}$-sodium ethylenediamine tetra-acetate depressed the rate of autolysis to a value close to that corresponding to zero ionic strength (Fig. 6). The autolysis of the isolated cell-wall fraction was found to be unaffected by repeated washing at $2^{\circ}$ with distilled water or with $0.2 \mathrm{M}-\mathrm{NaCl}, 0.2 \mathrm{M}-\mathrm{KCl}$ or $0.2 \mathrm{M}$-sodium acetate buffer at $\mathrm{pH} \mathbf{5}$ or $\mathrm{pH} \mathbf{5} \cdot \mathbf{8}$.

Autolysates of the cell wall of Staphylococcus aureus contained a factor which would lyse intact Micrococcus lysodeikticus (NCTC 2665) and dissolve the cell-wall fraction of old cultures of this organism (prepared as that of $S$. aureus) in $0.02 \mathrm{M}$-sodium phosphate buffer at $\mathrm{pH} 6.8$. It was also observed that M. lysodeikticus, harvested during the exponential phase of growth, became osmotically fragile and that the cell-wall fraction of organisms of this age autolysed under conditions similar to those applying to $S$. aureus.

A more detailed study of the lytic factor of the cell walls of Staphylococcus aureus and its possible relationship to lysozyme was not undertaken since it was not within the scope of the present work to characterize the system responsible for the autolysis of the cell wall but only to discover the optimal conditions for its operation. It was, however, pertinent to consider in more detail the mechanism of development of osmotic fragility from a morphological point of view.

\section{Morphological changes accompanying osmotic fragility}

There are three obvious types of change which might give rise to osmotic fragility: (1) the wall might be completely removed from the surface of the plasma membrane; (ii) the wall might undergo a change of structure or crosslinkage which would cause a uniform loss of tensile strength over its surface without appreciable change of weight; (iii) the wall might be lost or weakened at one or more particular sites on the surface of the cell. An attempt was made to decide between these alternatives by studying the morphology of the fragments of the cell wall and plasma membrane after exploding the "proto- 
plasts' osmotically. The suspensions which had undergone 'protoplast' release in $1.2 \mathrm{M}$-sucrose were osmotically exploded and the fragmented organisms were separated at $5^{\circ}$ into supernatant, plasma-membrane and cell-wall fractions as described in Table 2 . In Table 3 the weights of the fractions recovered from the 'protoplasts' released from organisms harvested

\section{Table 2. Explosion and fractionation of 'protoplasts' \\ of Staphylococcus aureus (strain Duncan)}

'Protoplasts' in $40 \mathrm{ml}$. autolysis medium added to $200 \mathrm{ml}$. 1.2 $\mathrm{M}-\mathrm{NaCl}$ and centrifuged for $2 \mathrm{hr}$. at 3,500 $\mathrm{g}$ at $15^{\circ}$.

Supernatant discarded.

Pellet: dispersed in $10 \mathrm{ml}$. supernatant and added to $100 \mathrm{ml}$. distilled water containing $0.1 \mathrm{mg}$. deoxyribonuclease (Streptodornase of American Cyanamid Co.) and, after $20 \mathrm{~min}$. at $20^{\circ}$, cooled to $5^{\circ}$ and centrifuged for $1 \mathrm{hr}$. at $20,000 \mathrm{G}$ at $5^{\circ}$.

Supernatant 1 .

Pellet: dispersed in $20 \mathrm{ml}$. distilled water and centrifuged for $1 \mathrm{hr}$. at $3,500 \mathrm{G}$ at $5^{\circ}$.

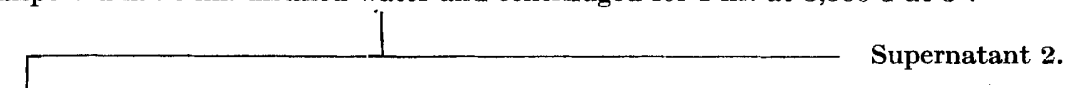

Pellet in three layers : dispersed separately into three lots of $10 \mathrm{ml}$. distilled water by gentle agitation, and recentrifuged separately for $1 \mathrm{hr}$. at $3,500 \mathrm{~g}$ at $5^{\circ}$.

The appropriate layers of the three fractions and their supernatants were recombined and the centrifuging repeated as above (in some cases through 2 further cycles) to give four practically homogeneous fractions as follows:

(a) Supernatant, combined with Supernatants 1 and 2 above.

(b) Light fraction, bright yellow (plasma-membrane fraction).

(c) Intermediate fraction, pure white (cell-wall fraction).

(d) Heavy fraction, pale yellow (intact-organisms fraction).

at a concentration corresponding to $2 \mathrm{mg}$. dry weight $/ \mathrm{ml}$. are compared with the weights of the same fractions obtained after mechanical disintegration of part of the same batch of washed suspension using the sonic disintegrator of H. Mickle as previously described (Mitchell \& Moyle, 1951). Phase-contrast microscopy of the fractions obtained from the autolytic 'protoplast' release showed that the 'plasma-membrane fraction' consisted of spherical shells of very low contrast, identical in appearance to the ghosts obtained from the protoplasts of Micrococcus lysodeikticus and Sarcina lutea (Mitchell \& Moyle, $1956 b$ ). When this fraction was washed for electron microscopy it disintegrated and became condensed into particles readily visible by phase-contrast microscopy. This material appeared identical in the electron microscope to the 'small particle fraction' isolated from mechanically disintegrated organisms (Mitchell \& Moyle, 1951) and the same total weight of it was obtained by the autolytic and mechanical disintegration methods (Table 3). The "plasmamembrane fraction' of the autolytic preparation also had the same enzymic composition as the 'small-particle fraction' of the mechanical disintegration method (Mitchell \& Moyle, 1956c). We suggested previously (Mitchell \& Moyle 1951) that the 'small particle-fraction' of the mechanically disintegrated 
organisms represented the plasma membrane of the intact cells because of its staining reactions, its high lipid content and the fact that there is sufficient to form a spherical shell $c$. $50 \AA$ thick and $0 \cdot 7 \mu$. in diameter when dry. Since we are now able to recover material of corresponding properties and total weight in the form of spherical shells, there seems to be little doubt that this material represents the plasma membrane.

Table 3. Weight and morphology of cell envelope fractions collected after mechanical or autolytic disintegration of Staphylococcus aureus (strain Duncan)

\begin{tabular}{|c|c|c|c|c|}
\hline \multirow[b]{2}{*}{ Material } & \multicolumn{2}{|c|}{ Mechanical treatment } & \multicolumn{2}{|c|}{ Autolytic treatment } \\
\hline & $\begin{array}{c}\text { Weight } \\
\text { (mg.) }\end{array}$ & Morphology & $\begin{array}{c}\text { Weight } \\
\text { (mg.) }\end{array}$ & Morphology \\
\hline Intact organisms & 100 & & 100 & $\theta$ \\
\hline Cell walls & $16 \cdot 6$ & Spherical shells & $12 \cdot 5$ & Hemispherical shells \\
\hline Plasma membranes & $9 \cdot 6$ & Small particles & $10 \cdot 2$ & Spherical shells \\
\hline
\end{tabular}

The weight of cell wall recovered from the use of the autolytic method was $25 \%$ less than from that of the mechanical one (Table 3 ), and the electron microscopy showed that whereas the material obtained from the mechanical disintegration consisted of punctured spherical shells (Pl. 1, fig. 1), that obtained from the autolytic method consisted entirely of hemispherical shells (Pl. 1, fig. 2). An examination of some hundreds of cell walls in photographs and on the fluorescent screen of the electron microscope showed that whereas the splits in the walls from the mechanically disintegrated organisms did not appear in any particular position relative to the equatorial ring (when visible), the edge of the autolytically produced hemispherical shells were invariably at right angles to the equatorial ring (when visible). Further, a pair of hemispheres was never seen to be joined by part of the edge. It therefore seemed reasonable to infer that the autolytic treatment resulted in the loss of an equatorial ribbon of cell wall, leaving the cell contents (in $1 \cdot 2 \mathrm{M}$-sucrose or other medium of equivalent osmotic pressure) as a protoplast capped by two mechanically separate hemispheres of cell wall.

It is necessary to emphasize that the fractionation of the osmotically exploded organisms described above was carried out on organisms harvested from cultures at a concentration corresponding to $c .2 \mathrm{mg}$. dry weight $/ \mathrm{ml}$. We have not so far been successful in obtaining satisfactory fractionation of osmotically exploded organisms from cultures harvested during rapid growth; perhaps the autolysis of the cell wall of younger organisms is not so strictly localized in an equatorial ribbon as in older ones. On the other hand, it is possible that after osmotic explosion the plasma membranes tend to adhere to the hemispherical caps of cell wall more in young than in old organisms.

\section{DISCUSSION}

The word 'protoplast' may conveniently be applied to the osmotically fragile staphylococci in which the cell wall has lost its tensile strength, but it would not be legitimate to remove the inverted commas except in cases where it can 
be shown that practically speaking none of the cell-wall material is still attached to the surface of the protoplast.

A number of studies on the autolytic systems of Gram-positive bacteria have indicated the presence of lysozyme-like enzymes. For instance, Meyer, Palmer, Thompson \& Khorazo (1936) observed the production of a lysozymelike factor by Sarcina sp., Webb (1951) found a similar factor in Clostridium welchii and Greenberg \& Halvorson (1955) found that lysozyme-like lytic enzymes were released from autolysing Bacillus cereus and B. terminalis. Recently, Richmond (1956) isolated and partially purified a lytic enzyme from an aerobic spore-forming rod which resembles egg-white lysozyme closely but is not identical with it. Stähelin (1953) observed autolytic spherical transformation in a particular strain of Bacillus anthracis in Ringer's solution.

It is possible that the main component of the autolytic systems which attack the cell walls of the cocci described in the present work is a lysozyme-like enzyme which acts on the same linkages in the cell wall as are attacked by egg-white lysozyme. Further work will be required to establish whether this may be true or whether other enzymes are mainly or partially implicated.

It is interesting that the ribbon of cell wall which appears to be digested or weakened by the autolytic system of Staphylococcus aureus (strain Duncan) should lie at right angles to the equatorial ring; for, since the successive planes of division in staphylococci lie at right angles, one might infer that the digested or weakened ribbon of wall corresponds to the division before (or possibly after) that represented by the equatorial ring.

The question arises as to the function of the autolytic systems in the growing organisms, since the autolytic activity is greater the greater the rate of growth. We can suggest two possible functions: (i) the lytic enzymes may normally have a synthetic function like, for instance, the enzymes synthesizing or degrading the glutamic acid polypeptides of the capsules of Bacillus subtilis and $B$. anthracis studied by Thorne (1956); (ii) the lytic enzymes may normally act as hydrolytic elements in the system responsible for the change of shape and disengagement of the cell walls of the dividing bacteria. In either case the activity of the lytic system would be expected to be greater the more rapid the rate of growth.

The release of the protoplasts of staphylococci from the mechanical protection of the cell wall makes possible the isolation and characterization of the plasma-membrane material and facilitates the study of the internal osmotic pressure and permeability properties of these organisms.

We are indebted to Miss Ann Gregor for technical assistance. This work has been supported by personal grants from the Scottish Hospital Endowments Research Trust, and by a grant for equipment from the Rockefeller Foundation. 


\section{REFERENCES}

Dixon, M. (1934). Manometric Methods. Cambridge University Press.

Greenberg, R. A. \& Halvorson, H. O. (1955). Studies on the autolytic substance produced by an aerobic spore forming bacterium. J. Bact. 69, 45.

Kern, R. A., Kingkade, M. J., Kern, S. F. \& Behrens, O. K. (1951). Characterization of the action of lysozyme on Staphylococcus aureus and on Micrococcus lysodeikticus. J. Bact. 61, 171.

Meyer, K., Palmer, J. W., Thompson, R. \& Khorazo, D. (1936). On the mechanism of lysozyme action. J. biol. Chem. 113, 479.

Mitchell, P. (1949). A new technique for stirred aerated culture. Nature, Lond. $164,846$.

Mrtcheld, P. \& Moyle, J. (1951). The glycerophosphoprotein complex envelope of Micrococcus pyogenes. J. gen. Microbiol. 5, 981.

Mitchell, P. \& MoYLe, J. (1956a). Osmotic function and structure in bacteria. In Bacterial Anatomy, Symp. Soc. gen. Microbiol. 6, 150; ed. E. T. C. Spooner \& B. A. D. Stocker. Cambridge University Press.

Mrtchell, P. \& Moyle, J. (1956 b). Liberation and osmotic properties of the protoplasts of Micrococcus lysodeikticus and Sarcina lutea. J. gen. Microbiol. 15, 512.

Mrtcheld, P. \& Moyle, J. (1956 c). The cytochrome system in the plasma-membrane of Staphylococcus aureus. Biochem. J. 64, 19P.

Richmond, M. H. (1957). Bacterial lysozyme. J. gen. Microbiol. 16, iv.

Stähelin, H. (1953). Über spontane sphärische Transformation von Milzbrandbazillen. Schreiz. Z. Path. 16, 892.

Thorne, C. B. (1956). Capsule formation and glutamyl polypeptide synthesis by Bacillus anthracis and Bacillus subtilis. In Bacterial Anatomy. Sixth Symp. Soc. gen. Microbiol. p. 68; ed. E. T. C. Spooner \& B. A. D. Stocker. Cambridge University Press.

WeBs, M. (1948). The action of lysozyme on heat killed Gram-positive microorganisms. J. gen. Microbiol. $2,260$.

WeBs, M. (1951). The influence of magnesium on cell division. 6. The action of certain hydrolytic enzymes on the filamentous and chain forms of Grampositive rod-shaped organisms. J. gen. Microbiol. 5, 496.

WeIBULL, C. (1953). Isolation of protoplasts from Bacillus megaterium by controlled treatment with lysozyme. J. Bact. 66, 688.

\section{EXPLANATION OF PLATE}

Fig. 1. Electron micrograph of cell-wall fraction of mechanically disintegrated Staphylococcus aureus (strain Duncan), shadowed at an angle of $15^{\circ}$ with gold-palladium. $\times 16,000$.

Fig. 2. Electron micrograph of cell-wall fraction of autolytically disintegrated Staphylococcus aureus (strain Duncan), shadowed at an angle of $15^{\circ}$ with gold-palladium. The edges of the hemispherical shells lie at right angles to the equatorial ridges when visible. $\times 16,000$. 
Journal of General Microbiology, Vol. 16, No. 1
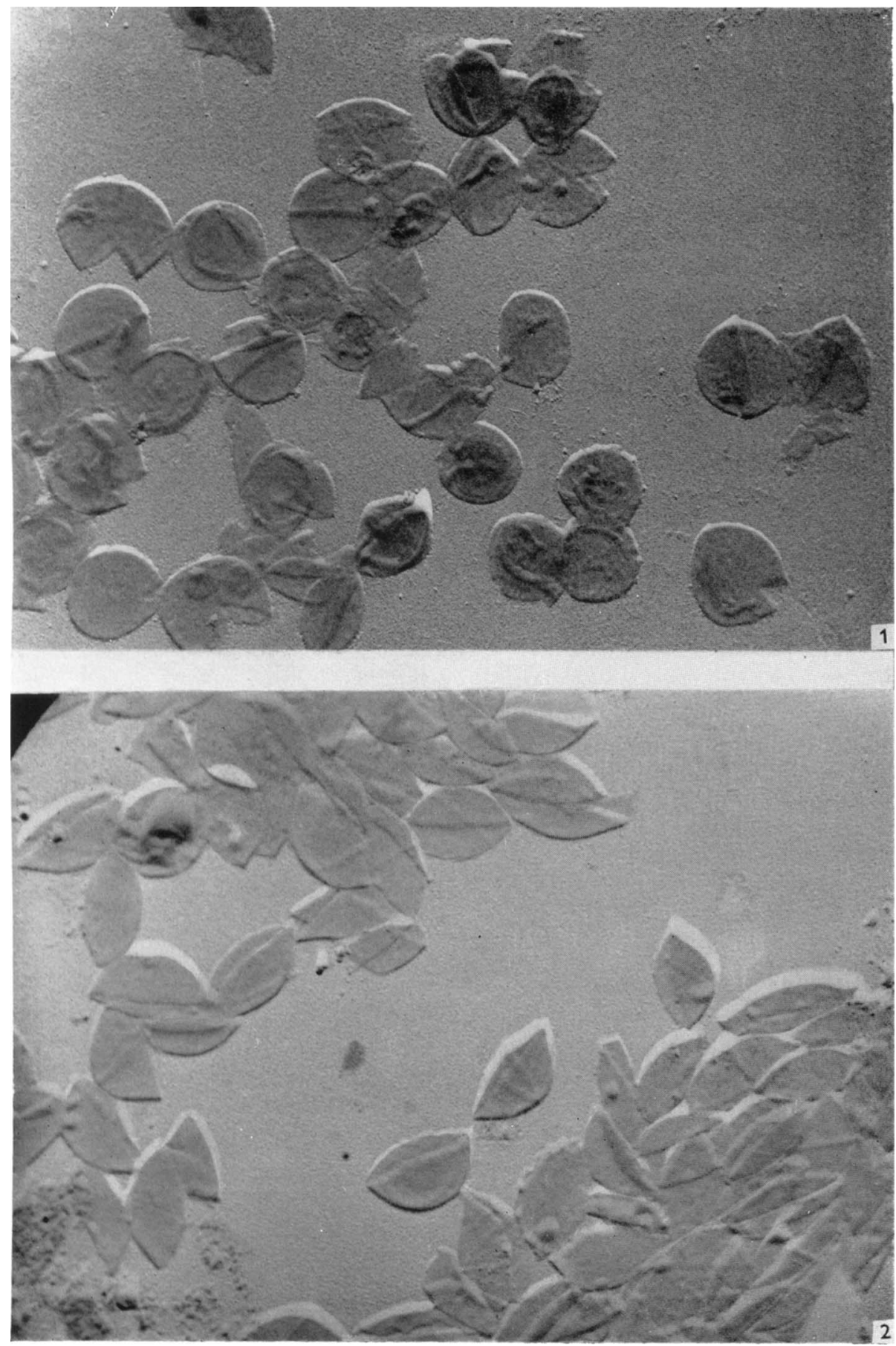

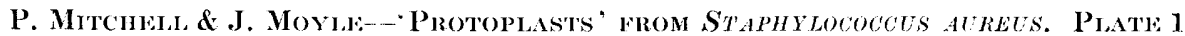
(Facing p. 194) 